Centro de Documentación, la sección Bases de Datos facilitará la consulta y acceso no sólo a la información de los bienes culturales andaluces como ya hemos comentado sino también a las fuentes de información del Patrimonio Histórico. Se incluirán las bases de datos propias y se ofrecerá el acceso a bases de datos sobre Patrimonio Histórico producidas por otros organismos, a través de enlaces establecidos con dichos recursos de información. Con ello, pretendemos ofrecer la integración de la información especializada sobre el Patrimonio Histórico a través de Internet.

\section{Notas}

I. Blanco, A., Madrid, V., Ortega, I. El Servicio de Información del Patrimonio Histórico de Andalucía: implantación y desarrollo. En: Actas de las VI Jornadas Españolas de Documentación. Valencia: FESABID, 1998. ISBN 84-33I-4609-X (obra completa)

2. Ortega, I., Limón, S. El Servidor Web del Instituto Andaluz del Patrimonio Histórico. En: Boletín del Instituto Andaluz del Patrimonio Histórico, año $\mathrm{V}, \mathrm{n}^{\circ}$ 19, junio 1997, pág. 139-146

3. Son varios los CD-Rom temáticos elaborados por el Centro de Documentación: Viviendas populares en Málaga, Inmuebles protegidos de las capitales andalu- zas, Megalitos de la provincia de Sevilla, Clausuras, Monasterios y Conventos de Cádiz, etc.

4. En la actualidad esta base de datos se denomina (DatARQUEOS).

Sánchez, F., Ortega, I., Díaz, J.M. Las bases de datos del Patrimonio Histórico Andaluz en el servidor web del IAPH. I ${ }^{\text {a }}$ fase: ARQUEOS. En: Boletín del Instituto Andaluz del Patrimonio Histórico, año VII, $n^{\circ} 29$, diciembre 1999, p. 216-219. ISSN II361867

5. A finales de año está prevista la culminación de la primera fase del Sistema Integrado del Patrimonio Histórico que está desarrollándose sobre Oracle y que incluirá información de Ciudades Históricas y Patrimonio Inmueble.

6. De momento sólo se han incluido algunas imágenes aunque está prevista la incorporación progresiva del banco de imágenes del IAPH.

7. En el Sistema Integrado está previsto que esa vinculación exista para todas las caracterizaciones.

8. García Gutiérrez, A. (Director): Tesauro de Patrimonio Histórico Andaluz. Versión 0. . Granada: Consejería de Cultura. Junta de Andalucía, 1998. Muñoz Cruz, V.: La normalización del Sistema de Información del Patrimonio Histórico de Andalucía: El Tesauro de Patrimonio Histórico. En: Boletín del Instituto Andaluz del Patrimonio Histórico, año IV, n 14, marzo 1996, pág. 110-115.

9. Tapia Martín, C.: Patrimonio Arquitectónico: la renovación del Sistema de Información SIBIA. En: Boletín del Instituto Andaluz del Patrimonio Histórico, año VII, n²8, septiembre 199, pág. 173-178.
10. La arquitectura defensiva se declaró de forma genérica en 1949 por esta razón la información existente en SIBIA sobre este tipo de arquitectura es muy escasa. Sin embargo desde DatARQUEOS sí se ha volcado a la nueva aplicación la arquitectura defensiva pues la información está más contrastada ya que se realizan revisiones periódicas del Inventario Arqueológico.

I I. Fernández, S.; Mondéjar, P.; Díaz, J.M. Arqueos: un modelo andaluz de gestión de la información arqueológica. En: Boletín del Instituto Andaluz del Patrimonio Histórico, año VIII, n 30, marzo 2000, pág. |43-149.

12. Hernández León, E;; Quintero Morón, V. El Patrimonio Etnológico en el sistema de Información del Patrimonio Histórico Andaluz. En: Boletín del Instituto Andaluz del Patrimonio Histórico, año Vl, n²3, junio 1998, pág. 117-121.

13. En la actualidad se está normalizando e informatizando el Inventario por este motivo la información a la que es posible acceder es muy básica. La información de Málaga es más completa pues esta provincia se informatizó para la elaboración de un CdRom de Viviendas Populares de esa provincia.

14. Ladrón de Guevara, C., Limón, S., Ortega, I. El Portal del Patrimonio Histórico de Andalucía. En: Boletín del Instituto Andaluz del Patrimonio Histórico, año VIII, n 33, diciembre 2000, pág. 205-2। I. ISSN I|36-1867

Valle Muñoz Cruz Isabel Ortega Vaquero Centro de Documentación del IAPH

\title{
El Instituto de Patrimonio Cultural de Venezuela
}

El Instituto de Patrimonio Cultural de Venezuela, el IPC, dispone de una completa a la vez que interesante página Web que refleja la labor que se realiza en dicha institución, y en general, el trabajo que se desarrolla en Venezuela a nivel gubernamental en lo relacionado con el Patrimonio Cultural.

Al realizar un recorrido por esta página, parece identificarse en numerosas ocasiones la huella de la Web del IAPH, concretamente de su Centro de Documentación, no tanto en lo tocante al diseño como en lo relativo a los contenidos. Es probable que la propia institución, el Instituto de Patrimonio Cultural Venezolano se haya inspirado en ocasiones o haya tomado como modelo la labor previamente realizada por el Instituto Andaluz de Patrimonio Histórico. No obstante, el IPC en Internet cuenta con evidentes aportaciones novedosas que se señalarán en este artículo.
Los pilares sobre los que se asientan los contenidos de esta página figuran en un menú que permanece fijo a la izquierda de la pantalla a lo largo de todo el recorrido por la Web. Entre los botones de este menú se encuentran Home, la página inicial, Acerca del IPC, una presentación o introducción al Instituto, Centro de Documentación, Bases de datos o Bienes Culturales Declarados, a los que se dedica una parte muy importante de la página Web y que se describirán más adelante, así como una serie de ejemplos concretos de elementos del Patrimonio con imágenes y descripciones.

El resto del menú nos permite acceder a los Proyectos del IPC, al Catálogo de Publicaciones y a las Publicaciones electrónicas, y a los Eventos, Noticias y Sitios de interés.

El Centro de Documentación se encarga de realizar todas las tareas que abarcan desde la selección y adquisición hasta la difusión de informa- ción relacionada con la protección del Patrimonio Cultural venezolano. Cuenta con fuentes documentales relativas a la conservación del patrimonio, fundamentalmente bibliográficas y fotográficas, así como con las bases de datos de los distintos inventarios de patrimonio.

El Centro de Documentación desarrolla el Proyecto de Inventario Nacional, integrado por diversas bases de datos temáticas que recogen toda la información registrada hasta el momento por la institución sobre los bienes integrantes del patrimonio cultural del país.

Entre estas bases de datos, el Preinventario de los Bienes Culturales y el Inventario de Testimonios y Procesos Culturales están disponibles en línea y permiten el acceso libre a la información que contienen a través de Internet.

Por otro lado, existen otras bases de datos que por el momento únicamente pueden con- 


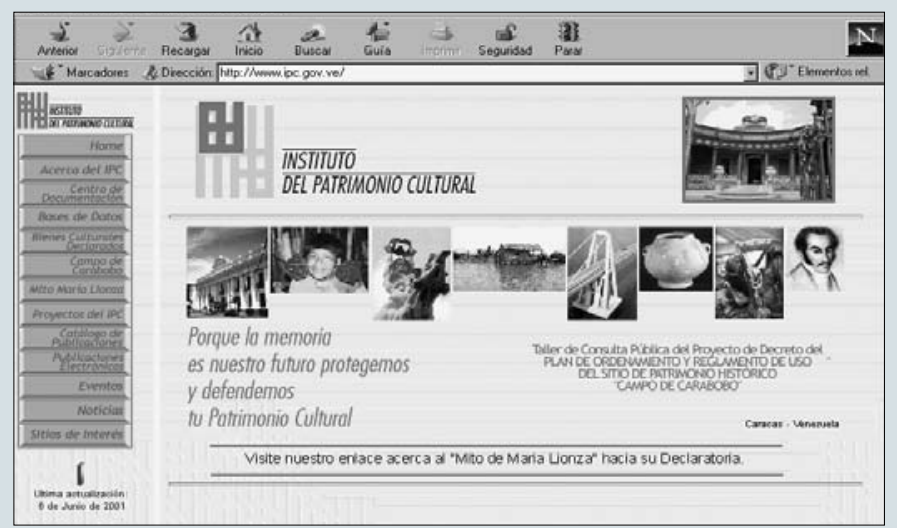

sultarse en el Centro de Documentación del IPC, aunque en un futuro pretenden activarlas para su consulta en línea. Se trata del Inventario de Edificaciones, con información de las construcciones arquitectónicas de mayor interés histórico-artístico y cultural del país; el Inventario de Colecciones, con información de objetos de valor documental e históricoartístico; el Inventario de Sitios Arqueológicos, que agrupa los más sitios más importantes conocidos o estudiados por los especialistas venezolanos; y la base de datos de Fuentes Documentales, que contiene información referencial de monografías relacionadas con le patrimonio cultural y las artes plásticas en general.

Entre las bases de datos actualmente accesibles en la red, el Preinventario de los Bienes Culturales ofrece la identificación cuantitativa de los bienes culturales de la mayor parte de los estados del país. Permite obtener consultar los bienes por su tipología: Patrimonio Arqueológico (y dentro de éste los cementerios, sitios funerarios, concheros, y un largo etcétera); Patrimonio Inmueble (edificaciones, sitios naturales y sitios urbanos, a su vez subdivididos en tipologías más específicas); Patrimonio Mueble (colección arqueológica, artes decorativas, artes visuales y documentos); y por último, Patrimonio Vivo (vestimentas, creación artística, gastronomía o rituales, entre otros).

Asimismo, es interesante destacar la base de datos del Inventario de Testimonios y Procesos Culturales (también disponible en Internet), como muestra de un ámbito del patrimonio histórico cultural poco o nada desarrollado en muchos casos en nuestro país y probablemente muy difícil de inventariar pero de indudable valor, en la que se incluye desde vestimenta propia de una zona o elementos de la gastronomía, hasta rituales y creencias, e incluso procesos productivos. Por el momento se encuentran registrados sólo los testimonios y procesos de cuatro estados: Amazonas, Apure, Aragua y Táchira, de los más de veinte que existen en el país.

La base de datos de Testimonios y Procesos Culturales permite realizar consultas a través de la denominación del elemento inventariado, del estado en el que se encuentra, por el contexto étnico de origen o por el tipo de testimonio o proceso de que se trata, pero no es posible cruzar estos campos.

En este sentido, las bases de datos del IPC, tal y como aparecen actualmente en su página Web, destacan más por la importancia de los contenidos que reflejan que por la calidad y el diseño de las bases de datos en sí como herramientas documentales de búsqueda y obtención de información en distintos formatos. No obstante, hay que decir que esta institución empezó a funcionar hace escasamente seis años y trabaja a nivel nacional, con la complejidad que esto implica en un país con tan inmensa riqueza cultural.

En cuanto a los servicios, el Centro de Documentación ofrece diversas modalidades de préstamos bibliotecarios, realiza búsquedas bibliográficas y dispone de una serie de servicios de Difusión Selectiva de Información, de referencia y orientación en búsquedas de información, etc. Además, se encarga de la realización del Catálogo de Publicaciones y de la gestión, difusión y venta de las publicaciones editadas por el IPC.

Entre estas publicaciones disponen de la colección Cuadernos del Patrimonio Cultural, con las series Inventarios y Difusión, la Colección Teoría e Investigación, ediciones especiales de determinadas obras, publicaciones electrónicas en CD-ROM y la Revista IPC. De todas estas colecciones y de las obras publicadas aparecen reseñas en la Web del IPC, en el botón Catálogo de Publicaciones, en el que también se explica el trámite para la adquisición de ejemplares a través de Internet.

Por otra parte, el botón Bienes Culturales Declarados proporciona acceso a los bienes protegidos por la legislación venezolana en los distintos estados, además de citar la normativa jurídica vigente sobre protección y de permitir el acceso a la declaración especíica de cada bien.

En el apartado Proyectos del IPC se describen los distintos proyectos o líneas de trabajo que el Instituto de Patrimonio Cultural desarrolla tanto en el ámbito nacional como a nivel regional. Se trata de temas muy diversos y dispares que van desde las declaraciones de Bienes de Interés Cultural hasta la revitalización del patrimonio oral de una zona, pasando por la promoción y difusión del patrimonio venezolano.

Asimismo, y como una forma más de difusión de la labor que viene desarrollando, el IPC expone en su página Web dos ejemplos del trabajo que está realizando en elementos específicos de su patrimonio cultural, el Campo de Carabobo y el Mito de María Lionza, de los que se ofrece documentación sobre los bienes e información relativa a los trabajos previos y las intervenciones previstas.

Por último, las secciones Eventos y Noticias destacan por su carácter práctico para todos aquéllos interesados en los cursos, talleres o confe- 
rencias del IPC, o incluso en intervenir en algunos de los proyectos relacionados con los bienes culturales, mientras que los Sitios de interés proporcionan enlaces a través de Internet a múltiples instituciones, fundamentalmente de ámbito nacional aunque también hay una sección dedicada a organismos internacionales, relacionadas con el Patrimonio Histórico y Cultural.

María Victoria Madrid Díaz Centro de Documentación, IAPH

\begin{tabular}{ll}
\hline FICHA DE LA WEB & \\
\hline URL PRINCIPAL & http://www.ipc.gov.ve/ \\
\hline TITULAR & Página elaborada por el Instituto de Patrimonio Cultural de Venezuela \\
\hline INFORMACIÓN DISPONIBLE & Buena (variada y útil) \\
\hline CALIDAD BASES DE DATOS & Media \\
\hline CALIDAD GRÁFICA & Media \\
\hline DISEÑO WEB & Medio \\
\hline FACILIDAD DE NAVEGACIÓN & Buena \\
\hline VELOCIDAD DE CARGA & Rápida \\
\hline ACTUALIZACIÓN & Buena
\end{tabular}

\section{Castillos en Internet}

E territorio andaluz cuenta en su haber con innumerables joyas inmobiliarias de gran interés histórico y cultural. De entre ellas, analizaremos en esta ocasión el lugar emblemático que en nuestra geografía ocupan los castillos y fortalezas defensivas. En Andalucía, tenemos en torno a 369 castillos y edificios defensivos declarados BIC (Bien de Interés Cultural), lo que nos hace reflexionar sobre el papel que estos edificios han jugado en la configuración del territorio y en el devenir de la historia de la región.

Todo ello, sin embargo, no se encuentra reflejado del mismo modo en Internet, encontrándose escasos ejemplos de sitios web que muestren de un modo profundo y detallado la historia de estos monumentos, de su emplazamiento, características constructivas, etc. Existen muchas reseñas breves, normalmente acompañadas de algunas imágenes, en sitios dedicados a promocionar el turismo de una determinada comarca, pueblo o ciudad. Como ejemplo, tenemos las referencias que sobre el Alcázar de los Reyes Cristianos de Córdoba podemos encontrar en:

http://www.uco.es/cordoba/.../flores.html, o en http://www.cyberspain.com/ciudades-patrimonio/fotos/coralc.htm

Por otro lado, también podemos encontrar sedes web monográficas que, sin embargo, muestran una información muy somera del edificio, como en el caso del Castillo de La Calahorra en La Calahorra (Granada), que cuenta con un breve recorrido por su estilo y singularidad constructiva, descripción de los elementos arquitectónicos externos, análisis del palacio interior, así como unos mapas de situación dentro de la geografía andaluza y de comunicación por carretera, todo ello acom- pañado de algunas imágenes en un total de seis páginas.

http://www.guadixymarquesado.org/castillo/ent rada.htm

En esta línea contamos también con la página web de la Torre de La Calahorra de Córdoba, hoy por hoy museo de esa ciudad, cuyo contenido nos habla de los espacios museísticos que se muestran en su interior, dedicados a aspectos destacados de la época de Al Andalus con apartados como: Acogida, Los filósofos, Ciencias y técnicas, El Apogeo, La Alhambra, Música, Mezquita, Viaje y Multivisión; aspectos que nos hablan de la época de mayor esplendor en los siglos XII y XIII en un total de once páginas y con algunas imágenes referenciales.

http://www.torrecalahorra.com/index_es.htm

Pero no todo lo que podemos encontrar en Internet sobre este tema está tratado de la misma manera, y por ello, después de estas referencias nos centramos a continuación en un ejemplo de análisis pormenorizado de un castillo en la web, donde a lo largo de 26 páginas podemos realizar un recorrido por sus aspectos constructivos, la situación geográfica, los planos, la historia, así como por los elementos socioculturales y antropológicos de una época -y por el entorno cultural y natural que lo rodea.

Este es el caso de la página web dedicada al Castillo de los Guzmán en Niebla, situado en la provincia de Huelva. Su página principal nos muestra un escudo de armas con la denominación del castillo en el centro, todo con una tipografía y tratamiento claramente medievales (efecto de pergamino en el fondo y letra tipo gótica o similar). En la parte inferior de la pági- na aparecen cuatro apartados que funcionan como entradas principales a la información interior que son: El Castillo, Niebla, Visita Virtual y Turismo. Situándonos con el ratón sobre cada uno de ellos, se despliega un submenú en forma de pergamino con todos los apartados que podemos encontrar en su interior relacionados con estos temas.

Para completar las posibilidades de acceso dentro de la página principal, en los extremos superiores izquierdo y derecho de la misma tenemos dos escudos que actúan también como entradas: uno hacia un bando informativo sobre los eventos estivales del castillo, y otro, hacia una tienda on-line.

Comenzando el recorrido por El Castillo, encontramos los siguientes apartados, de cuyo contenido pasamos a dar algunas pautas:

¿Qué es un castillo?, nos habla de sus orígenes y elementos; ¿Cuándo se hacen?, muestra su estilo señorial o de castillo-palacio mudéjar propio del siglo $\mathrm{XV}$, con el uso de barreras artilladas perfectamente adaptadas a los estragos; ¿Cómo se hicieron los castillos?, señala que se debían hacer con permiso real, dependiendo de los materiales de la zona, y con presupuesto de reparación procedente de impuestos especiales aplicados en las villas o aldeas dependientes; Emplazamiento de los Castillos, nos indica la gran variedad de lugares elegidos para su construcción, desde peñas inaccesibles a vaguadas para esconderse de la artillería; asimismo, la relación con las villas o ciudades era muy variada; Los constructores de un castillo, indica que eran los canteros o maestros de cantería los que se atribuían normalmente la traza y la ejecución material de la obra; finalmente, El Castillo y Alcázar de 